\title{
PIONEER
}

VOLUME 12, Issue 2, December 2020: 88 - 102

\section{THE PROBLEMS OF GENERATING IDEAS FACED BY ENGLISH LANGUAGE STUDENTS IN RESEARCH PROPOSAL WRITING}

\author{
${ }^{1}$ Sary Eka Wahyuni \\ ${ }^{1}$ Universitas Muhammadiyah Malang \\ ${ }^{1}$ saryekawahyuni@gmail.com \\ ${ }^{2}$ Nina Inayati \\ ${ }^{2}$ Universitas Muhammadiyah Malang \\ 2nina@umm.ac.id
}

\begin{abstract}
Generating ideas plays the key role in the initial phase of writing process, but not many empirical research is available in the literature that address the problems that students face in generating ideas, especially during research proposal writing. The current study aims to find out students' problems in generating ideas in writing the research proposal. This descriptive study mainly collected the data through survey and interview involving seventh semester students who were in their initial phase of drafting research proposal for their final projects. The data were then analyzed and presented using descriptive quantitative method. The findings indicate that most of the students' reported facing problems when generating ideas during the initial phase of research writing. Data analysis show that the problems range from the topic development, theoretical frameworks identification, relevant theory search, trusted sources evaluation, research ideas and relevant theory connection, as well as problems and theory assessment. Some pedagogical implications in light of the findings are discussed following the presentation of the results of the study, such as the importance to provide constructive feedback in a timely manner, and discussing ways to evaluate quality resources.
\end{abstract}

Keywords: generating ideas, problem, research proposal, writing

\section{INTRODUCTION}

As one of the productive skills, writing requires a person to produce linguistic expressions in the form of written text. Writing is a complex activity which is frequently considered as a task that demands high cognitive process and ability, and it involves the 'coordination of several mental activities' (Mertens, 2010). Writing process requires the brain to think in a complex manner to process various information that will be put into the written forms. Writing is about creating a new written product which lend its name as the productive skill, and it is also considered a reflective skill as it shows the knowledge and the analytical skills of the writers (Allal, Chanquoy, \& Largy, 2004). According to Knorr, Heine, \& Engberg (2014), the activity of writing involves some social and individual aspects that influence how the text is composed. Through these 
written texts, the writer interacts with the readers to convey the contexts of the topic which are formed by the writer's social, cultural and historical instruments, as well as his/her practices and understanding.

A writer needs to be cautious in using words when writing their composition. As suggested by Sova (2004), writing is an influential instrument that possess the capability to alter one's opinions, construct or destruct understanding, build or break relationships, and establish positive or negative perceptions in the lives of the readers. Therefore, care should always be given when determining the words in the writing in order to avoid differing perceptions between the writer and the readers. In addition, Oshima \& Hogue (2009) also maintain that writing is a process involving the creation of ideas, followed by the systematic organization of those ideas, then the formulation of the predetermined ideas or topics into the first rought draft, and finally the revision and editing of the rough draft to polish it and créate the final draft. This process shows how complex writing activity is as it involves cognitively demanding process which results in the creation of a means of social interaction between the readers and the writers.

University students in Indonesia are required to do this process as part of their daily academic activity which eventually lead them to create a written academic research report at the end of their study. As the initial process of the research project, they need to write their research proposal using the style of academic writing. A research proposal, according to Creswell (2012), is a specific plan and outline developed before a researcher does the actual study to be written in a research report. However, many students report facing difficulties in producing pieces of academic writing (Al Naqbi, 2011 \& Badi, 2015) as it is considered a complex process requiring them to engage in extensive mental and cognitive activities (Al Fadda, 2012). In addition, Wang \& Yang (2012) also suggest that several studies have covered this area in order to find out the university students' difficulties in writing research proposal, as well as their cognitive growth process. This has been one of the main reasons that university students are required to pass the academic writing course which is believed to assist them to eventually be able to publish their research report.

As the initial phase that students need to complete in their research, writing research proposal requires students to create some plans before the proposal writing activity commences. As the first step, students need to do some planning activities to 
clearly outline their research progression. However, many students face problems of various nature in this very phase because of the complexity of the cognitive process involved in writing and, as suggested by Torrance, Waes, \& Galbraith, (2007), studies repetitively show that many 'writers are constrained by the capacity of their working memory'. Writing process is closely related to the student's memory as it involves the knowledge and information that they have previously received. Writing process is an inseparable part of students' life, therefore, students must be well trained to be skillful in academic writing in order to complete their study.

\section{The Cognitive Process of Writing}

Writing is more than just putting abstract ideas into visual written forms as it involves a deep cognitive process to allow the creation of a good written text. Writing activity involves a process of understanding that are reflected when a writer produces and evaluates their thoughts as opposed to a mere transfer of abstract ideas into written words (Torrance et al., 2007). During the process of language production, close connection of knowledge and new information acquired through experience continually happen in the writer's brain. In this case, understanding of a topic to write is essential in order to create compositions or written texts that are well-written and contextappropriate, supported by mutually related topics, sentences and paragraphs.

According to Flower \& Hayes (1981), the cognitive process of writing comprises of a three-unit model that reflects the development of written product which the completion stage is organized in a sequence that are well-structured and inter-related. With his three-unit model of writing act, Flower and Hayes explain that the process of writing involves the task environment, the author's long-term memory, and the actual 'writing process'. The task environment comprises all aspects related to the author's knowledge, which initial process commonly involve the creation of rhetorical problem or assignment. Further, Flower and Hayes also emphasize that the most essential component is the rhetorical problem itself as it serves as the start where the author will respond by offering some solutions through their writing. Each person may have different ways to solve a problem, which is also the case in the process of writing and approaching a rhetorical problem. At the time of writing, a writer may face various constraints, among others are incoherent writing, or difficulty in connecting new ideas 
with the existing theories available in the literature. Therefore, many consider that writing is a very demanding activity as it requires a deep cognitive activity where the writer connect the knowledge in their long-term memory to the writing plan arrangement in response to the rhetorical problem.

Next, the long-term memory of the author is the second model. Flower and Hayes (1981) revealed that long-term memory implicates everything held in the mind in the shape of information and knowledge concerning a topic or writing scheme. The hindrance faced by the authors regarding long-term memory is the difficulty in rearranging or adjusting information or knowledge to correspond to the requirements of rhetorical problems.

Writing process becomes the following element in the model of writing. They defined the writing process involved primary processes containing planning, translating, and reviewing. Planning which is the first sub-process is knowledge representation that is used in writing, such as broad information represented using keywords or codes. There are three sub-processes in the planning process, namely generating ideas, organizing ideas and setting goals. Long-term memory is involved when the process of generating ideas aims to regain relevant information to the topic that is going to be written. After the writer's memory contains the structured information, an idea is organized so that the structure of the idea is more valuable. The third sub-process is setting goals, which involves the process of directing the generated ideas into specific writing goals. After planning continued by translating process. Flower and Hayes (1981) states that translating is the encoding process of anything that has been done in the processes of planning into language. In other words, it is the process of transforming the ideas into a visible language. The process is followed by a process of reviewing which is separated in two sub processes, they are evaluation and revision. The process where the writer re-reads what has been written to translate further or systematically to assess or correct the text is a form of reviewing process.

This paper focuses on the first sub-process that writers do during the writing process, which is generating ideas. As such, the topic is further elaborated in the next section in order to provide a deeper discussion of the current literature relevant to it. 


\section{Generating Ideas in Writing}

Generating ideas includes the identification of probe memory used to explore long-term memory which usually have a basis on a written topic. In the process the writers do evaluate the output that is looking for memory and if the output is relevant or important then it could be used. This process will keep on until the desirable content is sufficient (Crossley, Muldner, \& McNamara, 2016). Finding topics is the most challenging and difficult to predict and it is the most important activity in writing (Kennedy, Kennedy, \& Muth, 2011). Therefore, in writing activities the generating ideas is a process that must be involved in writing activities where the aim is to yield or find a topic. In addition, it is not only idea to gain a topic, but more to generate ideas when a topic has been discovered to enrich the writing content that the writer wants to write according to the topic that already chosen. Allal et al. (2004) express that generating ideas is more productive when it is done before the written text produced by the author rather than it is carried out at the same time when the author is producing text. Furthermore, Miftah (2011) argues that generating ideas is the skill of adding, extending or connecting given ideas by employing prior knowledge or compiling information. Touching on the theory of Flower \& Hayes (1981) and Miftah (2011) mentioned above, researchers involve evaluating, expanding, and connecting to be the base of developing the questionnaires.

Generating ideas can be defined as a slightly complex process because it links to long-term memory. In consequence, there are definitely issues that emerge in this process. According to the study conducted by Safitri (2019), it is found that there are several issues faced by students when generating their ideas in their writing research proposal involving aspects of expanding, connecting and adding few things like topics, gaps, theories and sources gained from the preliminary research before developing the questionnaires. Expanding aspect is the first problem that the most dominant problem happened in terms of topic and theory. Students faced trouble in expanding new information according to the topic they use in their study. In addition, they also come across the difficulty in discovering the theories that are suitable to the topic that are used to support and extend their topic that were not in advance used by prior researchers.

Connecting becomes the second aspect that the dominant problem appears in form the topics, theories, and also sources. The students faced trouble in finding the topic that suits them with what they desire or their interest. In addition, the difficulties in linking 
the similar topics that differentiate among student research and prior research and also the choosing ideas related to the prior research. In addition to the problems in connecting the topics, they also hold problems in linking with the theories. Problems connected to the theories are the difficulties in connecting issues that happen in the field and also the research ideas with theories. Apart from that connecting with the sources also became the problem. In this case they have difficulty in associating trusted sources with the research ideas.

Evaluating is the last aspect. In this aspect the students hold problems in evaluating the topics that they gained in the field and there is no study that has been done before. In addition, the students faced problems in evaluating the sources before being used as a source of theoretical framework. Majority students experienced problems in all aspects and the dominant point is the point of topic. Somehow, the current study employs the generating ideas issues and involves the distinct subject with the prior study to reveal the problems of the dissimilar place.

Although studies related to the writing are quite abundantly available in the literature, specific study focusing on the initial process of research proposal writing is still very scarce. Therefore, this study seeks to fill in the gap by expanding on Safitri's (2019) study in the hope to understand more about the nature of the problems that students face when generating ideas for their research. This study seeks to answer the research question of what are the students' problems in generating ideas for writing research proposal. To be more specific, this study aims to find students problems related to the theory, topic, gap and source when they are expanded, connected and evaluated during the process of generating ideas when writing a research proposal. The understanding obtained from this study is in the form of mapping out students' initial problems in planning their research, and thus is highly significance especially for higher education institution in order to better facilitate students' research.

\section{METHOD}

The design of the current study is descriptive research aimed to investigate the university students' problems in generating ideas in writing research proposal. Descriptive research is a research intended to investigate the circumstances, conditions or activities, among other, of a specific issue in its natural environment (Arikunto, 2013, 
Atmowardoyo, 2018).

This research involved seventh semester students who enrolled in the Research Writing course as the population. They were students of English Language Education Department Students, with the total of 15 cohorts, each consisting of 12 students. In total, there were 180 students population targeted in this study.

The current study used survey as the techniques of data collection. Questionnaire is a form that is used in a research to be completed by participants and then returned to the researcher (Creswell, 2012). The questionnaire employed in this study was a close ended one, aimed to tap on the student's problems in generating ideas in writing research proposal. The researcher distributed the questionaire to all of the fifteen-research writing cohorts through Google Form and involved random students in each class. This is conducted in accordance with Sugiyono's (2012) suggestion that homogeneous population can use random sampling techniques without regard to strata that exist in these populations and that the decent sample size in the study is 30 to 500 . At the end of the data collection process, 59 students completed the questionnaire and it was considered sufficient for the study.

The questionnaire in this study was adapted from a previous study conducted by Safitri (2019) in order to find out the students' problems in generating ideas when they write their research proposal. There are two parts in the questionnaire. The first part covers the respondents' identity, while the second part focuses on tapping the students' problems in generating ideas. The researcher validated the questionnaire expert validity involving an expert in the field of English Language Teaching, and face validity involving five students of English Language Education Department to try out the questionnaire. The questionnaire was then revised based on their inputs.

After all the data from the survey were obtained, they are analyzed descriptively. The data analysis was conducted based on the six-step procedure suggested by Creswell (2012) namely; preparing and analyzing the data, reading all collected data, encoding the data, using codes to develop more general images of data descriptions and themes, using narratives and or numeric to represent findings, and interpreting the meaning of the findings. The results of the data analysis is presented in the next section. 


\section{FINDINGS AND DISCUSSION}

\section{Findings}

The analysis results of survey and interview data show that students faced difficulties in the four aspects that were tapped; topic, source, theory, and gap. The difficulty was in terms of finding/extending, connecting, and evaluating of those aspects when generating ideas for their research proposal. The detail of the analysis results of the findings are presented below. They are arranged in accordance with the level of difficulties indicated by the survey results, starting for the most difficult one to the least difficult: theory, source, topic and gap.

\section{Theory}

The first and foremost problem in generating idea according to the survey respondents were in terms of finding and evaluating relevant theory to be used for research. As noted in table 1, the problems related to theory was the highest in percentage in comparison to other aspects, this means that students regarded this aspect to be the most difficult. To be more specific, almost all students $(84.7 \%)$ reported that finding and extending original theory was problematic, and $61 \%$ also reported that finding theoretical framework relevant to their research topic was difficult. In addition, evaluating the research problem (62.7\%) and ideas (57.6\%) and connect it to theories were also reported as difficult. Finally, another difficulty related to theory was reported, especially in terms of connecting it with the problems in the field (57.7\%) and the research ideas $(52 \%)$.

Table 1. Generating Ideas problems in point of theory

\begin{tabular}{clc}
\hline No & \multicolumn{1}{c}{ Statements } & Result \\
\hline 1 & Find a new theory that was never used by previous research & $84.70 \%$ \\
\hline 2 & $\begin{array}{l}\text { Evaluate the problem and find a theory that is appropriate with the } \\
\text { problem }\end{array}$ & $62.70 \%$ \\
\hline 3 & $\begin{array}{l}\text { Find a theoretical framework that could support and develop my } \\
\text { research topic }\end{array}$ & $61 \%$ \\
\hline 4 & Connect problems in the field with the theory & $57.70 \%$ \\
\hline 5 & $\begin{array}{l}\text { Evaluate research ideas and find theories that are appropriate with the } \\
\text { ideas }\end{array}$ & $57.60 \%$ \\
\hline 6 & Connect research ideas with theories & $52 \%$ \\
\hline
\end{tabular}


The results of interview also support the survey analysis. The interview results showed that the students have problems in finding a theoretical framework that could support and develop their research topics. It is supported by the statement "I took English for Young Learners for my topic so there must be a theory and there must be a source. My supervisor said that there are a lot theories and sources but I have to look for the ones closest to my topic. In almost all of the previous research that I saw, there is no one discussing about my topic, so it's difficult there." While another problem tapped during interview was related with difficulties in finding original theories that have never been used by previous studies that aim to support their writing. Additionally, the students also expressed that they had difficulty in connecting the research idea with the theory, "When I already have ideas, I'm confused to combine those ideas, for example, I want to connect it with the theory, which theory will I use that fits?" One of them also revealed "well if I have found it all, surely it will be evaluated at the end before it is writtenn into my writing, and it's quite difficult though, I also need to know if the theory is correct or not, valid or not, I have to double-check to several sources." From these statements, they confirm that students do faced difficulties in finding a theory that is appropriate with their research ideas and in evaluating those theories.

\section{Source}

The second difficulty reported by most respondents was in terms of the sources of ideas when writing research proposal. $64.4 \%$ student respondents reported that evaluating the academic sources to be used as the theoretical basis in their research as difficult. In addition to the problem in evaluating, the problem in finding and extending the sources related to their research ideas were also challenging $(56 \%)$. Finally, some students $(23.7 \%)$ also noted that it was difficult for them to determine some previous studies that were relevant to their research ideas. Table 2 illustrates the students' problems related to the aspect of source.

Table 2. Generating Ideas problems in the aspect of source

\begin{tabular}{clc}
\hline No & \multicolumn{1}{c}{ Statements } & Result \\
\hline 1 & Evaluate the sources I found before as a theoretical framework & $64.40 \%$ \\
\hline 2 & Find trusted sources or links that are related to my research ideas & $56 \%$ \\
\hline
\end{tabular}


Student respondents' difficulty is finding, extending, evaluating and connecting the sources for their research proposal was also supported by the results of the interview. First, such difficulty was found in evaluating the sources they have found for their theoretical framework, such as in the following statement "it is difficult to relate one theory with another theory, for mastering the theory that I am using, is it true or not relate to my topic?" The next problem is about finding a reliable source that should be aligned with their research. This is due to the limited access to good journals or books online, or due to the validity of the sources that they have found, mostly online. It is supported by the statement "I have a problem in sources and theory, limited access, for example, I want to download, but I cannot find theories that fit my topic", besides that "it's hard. I am looking for a trustworthy and valid reference. There are a lot of papers in the Internet, but sometimes, the source does not exist or the bibliography does not exist, so I do not know which one is valid, which one is not."

\section{Topic}

The next aspect becoming the source of difficulty for students when generating ideas in writing research proposal was in terms of topic. To be more specific, the biggest problem lies in the evaluation of the topic to ensure that the research gap does exist $(59.9 \%)$. Then, the other problems related to the choice of topic for research that students reported difficult was about finding and extending the topic (55.9\%), developing the topic (47.5\%) and finding the topic of research itself (47.5\%). Table 3 presents the more detailed account of survey analysis results for the aspect of finding, extending, evaluating and connecting the topic of research.

Table 3. Generating ideas problems in the aspect of topic

\begin{tabular}{clr}
\hline No & \multicolumn{1}{c}{ Statements } & Result \\
\hline 1 & $\begin{array}{l}\text { Evaluate the topics that I find to make sure that there is no similar } \\
\text { research before }\end{array}$ & $59.40 \%$ \\
\hline 2 & Find research ideas that can develop information for my research topic & $55.90 \%$ \\
\hline 3 & Develop the topic that I find as my research & $47.50 \%$ \\
\hline 4 & Find a topic that suits my interests & $47.50 \%$ \\
\hline 5 & Evaluate problems that I find as topics that I want to use & $32.20 \%$ \\
\hline
\end{tabular}




\begin{tabular}{clc}
\hline 6 & $\begin{array}{l}\text { Evaluate the similarities and differences between my research and } \\
\text { previous research. }\end{array}$ & $28.80 \%$ \\
\hline 7 & $\begin{array}{l}\text { Read the appropriate research problem that can develop my knowledge } \\
\text { to find research topics }\end{array}$ & $23.70 \%$ \\
\hline 8 & Find a problem related to the research field & $23.70 \%$ \\
\hline 9 & Develop research questions that are in line with my topic & $22 \%$ \\
\hline 10 & Find a similar topic related to the topic I want to use & $20.40 \%$ \\
\hline
\end{tabular}

The interview results also supported the findings in the survey in terms of student difficulty related to topic. One interviewee noted that "when I have got the idea of the topic, the next problem is how I develop the topic, if I get the topic A how do I go to BCD, from the research itself we have to pay attention to the sources as well because that is academic writing so I cannot write carelessly."

\section{Gap}

The problem in gap indicates that the student respondents faced difficulty when they try to clarify the difference between their research and previous studies. For this problem, the main challenge that student respondents faced was the difficulty in clearly showing the difference of their research idea with regard to the difference with the previous studies even though the topic is similar (56\%). Other problems mentioned were finding previous research related to the topic and put it into a research idea $(27 \%)$ and choosing research ideas related to certain previous research $(13.6 \%)$. Table 4 presents the detailed account of students' problems related to finding, extending, evaluating and connecting the research gap when writing research proposal.

Table 4. Generating Ideas problems in point of gap

\begin{tabular}{clc}
\hline No & \multicolumn{1}{c}{ Statements } & Result \\
\hline 1 & $\begin{array}{l}\text { Can clearly show the difference between my research and previous } \\
\text { studies even though the topic is similar }\end{array}$ & $56 \%$ \\
\hline 2 & $\begin{array}{l}\text { Find the results of previous research related to my topic and put it into a } \\
\text { research idea }\end{array}$ & $27.10 \%$ \\
\hline 3 & Choose research ideas related to previous research & $13.60 \%$ \\
\hline
\end{tabular}

\section{Discussion}

The first discussion is about the students' problems in generating ideas in writing their research proposal. Allal et al. (2004), in his notion, asserted that generating ideas is more productive when it is achieved before the writer generates the written text. In other 
words, it would be more productive if the process of generating ideas was done before the actual process of writing; the writer thought first about what he wanted to write so that the process of writing could be effective. Nevertheless, the current study found that the process of finding and generating ideas do not come easily, especially for students when they are in the initial phase of writing their research proposal.

One of the notable issues in generating ideas is in the aspect of extending the topic. Some students expressed that trying to develop the topics that they find for their research was highly challenging. This is a tricky issue as Kennedy, Kennedy, \& Muth (2011) have pointed out that finding a topic is the first activity in writing because it is the most challenging and the most difficult to do. Not only in terms of finding but the difficulty also arises in the process of developing. It cannot be denied that determining the topic is crucial in the writing process, but the problem procedes when students have found the topic and confuse to develop what ideas to put next, then the processes in the writing could be hampered. In this case, Safitri (2019) also found that the majority of students experienced problems in terms of developing new information that could support their topic. Although the detail of the findings are different, the general problems found was in terms of the topic. In short, because the students experienced more problems in the aspect of topic, this should become the first point to offer solutions, such as through the use of various types of stimulation activities to help students brainstorm topics that are of interest to them. In addition, differentiated instruction as suggested by Tanjung \& Ashadi (2019) could also be a solution in order to cater for students' different styles in learning, especially in learning how to write.

Another notable finding was in terms of connecting research ideas with the existing theories. As Torrance, Waes, \& Galbraith (2007) suggested, persons will not be able to start their writing if they do not have ideas or access to the ideas and 'If someone has an idea but there is no way to express it, there is no communication happening'. This statement is closely related to the current study findings which found that students faced difficulty in relating their chosen research idea with the literature that could serve as the theoretical basis for their research. Some detail of the difficulty was, for example in finding trusted sources that are related to their research ideas as academic writing requires reliable literature as supports. Other than that, this finding was also in line with Safitri (2019) who revealed that most students faced difficulties in connecting the ideas with 
the theories and also to connect with trusted sources that are relevant to their research ideas.

Further, Flower \& Hayes (1981) also stated that generating ideas involve evaluation. During evaluation process, writers assess their chosen topic and other sources to broaden their ideas, as well as judging their theories and gap so that they have clear content to write their text, in this case research proposals. The current study shows that students' generally face difficulties in evaluating their research ideas and find theories that accordance with those ideas and also evaluating sources that they found earlier as a theoretical framework. According to Crossley, Muldner, \& McNamara (2016) in the initial writing process, the writer evaluates the output of writing by looking into their own memory and if the output is considered relevant or important, it can be used. The process will continue until the desired content is considered sufficient. In fact, evaluating is not as easy as imagined so that when students have difficulty in it, they could fail to evaluate the output of writing that comes from their long-term memory. In other words, they have difficulty evaluating their ideas with the topics they take. Students also experience problems with source evaluation before they make their theoretical frameworks. This finding is also in accordance with the results found by Safitri (2019) who found that the most difficulty arises was in terms of sources, which means they have difficulty in evaluating the sources to be used as the framework of thinking. In this case, helping students with various ways to evaluate sources for academic writing, especially those obtained online, is considered essential for academic writing course. In addition, providing timely and constructive feedback also plays a keyrole in assisting student writing in general (Amelia, 2020, Mulati, Nurkamto \& Drajati, 2020), especially during the evaluation phase.

\section{CONCLUSION AND SUGGESTION}

This paper aims to identify students problems in generating ideas when writing research proposals, and the results of data analysis from survey and interview have revealed that most student respondents did experienced problems. From the four aspects that are tapped in the survey, students reported problems in terms of finding/extending, connecting, and evaluating the topic for the research that they will do, the sources of literature support for the topic, the theoretical bases for their research ideas, and the gap. 
The most challenging problem that students faced was in terms of theory, especially in finding and evaluating relevant theories that they could use to support their research ideas. The second aspect most challenging for the students was the source, especially in terms of finding and evaluating the trustworthiness of the sources to be used in their research proposal. The next problem was related to the topic, students reported that finding, evaluating and developing the topic to be used in research to be highly challenging. Finally, in terms of gap, students reported the most difficult problem was in finding and clearly showing the gap of their research idea with the previous studies related to their research.

Because of the limited research with regards to generating ideas, future research is suggested to continue the research in term of writing especially in the generating ideas. Other than that, future research can also extend to generating ideas when researching the specific language skills such as speaking, reading, and also listening. The current research involved English Language department students as the subject. Therefore, future research could also involve other subjects.

\section{REFERENCES}

Al Fadda, H. (2012). Difficulties in Academic Writing: From the Perspective of King Saud University Postgraduate Students. English Language Teaching, 5(3), 123130. https://doi.org/10.5539/elt.v5n3p123

Allal, L., Chanquoy, L., \& Largy, P. (Eds.). (2004). Revision: Cognitive and Instructional Processes (Vol. 13). https://doi.org/10.1007/978-94-007-1048-1

Al Naqbi, S. (2011). The use of mind mapping to develop writing skills in UAE schools. Education, Business and Society: Contemporary Middle Eastern, Vol. 4 (2). Doi: 10.1108/17537981111143855

Amelia, R. (2020). Students'perception on employing self-directed feedback in writing. JOALL (Journal of Applied Linguistics \& Literature), 5(1), 60-70.

Arikunto, P. D. (2013). Prosedur Penelitian; Suatu Pendekatan Praktik. Jakarta: PT Rineka Cipta

Atmowardoyo, H. (2018). Research Methods in TEFL Studies: Descriptive Research, Case Study, Error. Journal of Language Teaching and Research, Vol. 9(1). doi: http://dx.doi.org/10.17507/jltr.0901.25

Badi, I. A. H. Al. (2015). Academic writing difficulties of ESL learners. WEI International Academic Conference Proceedings, 65-78. 
Creswell, J. W. (2012). Educational Research: Planning, Conducting, and Evaluating Quantitative and Qualitative Research (4th ed). Retrieved from https://sci.booksdescr.com/

Crossley, S. A., Muldner, K., \& McNamara, D. S. (2016). Idea Generation in Student Writing: Computational Assessments and Links to Successful Writing. Written Communication, 33(3), 328-354. https://doi.org/10.1177/0741088316650178

Flower, L., \& Hayes, J. R. (1981). A Cognitive Process Theory of Writing. College Composition and Communication, 32(4), 365. https://doi.org/10.2307/356600

Kennedy, X. J., Kennedy, D. M., \& Muth, M. F. (2011). The Bedford Guide for Collage Writers (Ninth Edit). New York: Bedford/St. Martin's.

Knorr, D., Heine, C., \& Engberg, J. (2014). Methods in Writing Process Research. New York.

Mertens, N. L. (2010). Writing: Processes, Tools and Techniques. In N. L. Mertens (Ed.), New York. Retrieved from libgen.pw

Miftah, M. Z. (2011). Mind Mapping: The Way to Generate and Organize Ideas. (October 2011). Retrieved from https://www.researchgate.net/publication/308888150_Mind_Mapping_The_ way_to_gen erate_and_organize_ideas

Mulati, D. F., Nurkamto, J., \& Drajati, N. A. (2020). The teachers'beliefs in teacher written corrective feedback on the students'writing. JOALL (Journal of Applied Linguistics \& Literature), 5(1), 1-10.

Oshima, A., \& Hogue, A. (2009). Writing Academic English (Fourth). Upper Sadder River: Pearson Educations.

Safitri, R. D. (2019). Students' Problem S in Generating Ideas to Write research Proposal in Seminar Proposal Course. UIN Sunan Ampel.

Sova. (2004). Writing Clearly A Self-Teaching Guide. In John Wiley \& Sons,

Inc. Education, Business and Society: Contemporary Middle Eastern Issues, 4(2), 120133. https://doi.org/10.1108/17537981111143855

Sugiyono. (2012). Metode Penelitian Pendidikan; Pendekatan kuantitatif, Kualitatif, dan $R \& D$. Bandung: Alfabeta.

Tanjung, P. A., \& Ashadi, A. (2019). Differentiated instruction in accommodating individual differences of efl students. Celtic: A Journal of Culture, English Language Teaching, Literature, \& Linguistics, 6(2), 63-72.

Torrance, et al., (2007). Writing and Cognition: Research and Application. In Encyclopedia of Language \& Linguistics. https://doi.org/10.1016/b0-08- 0448542/00867-1

Wang, X., \& Yang, L. (2012). Problems and Strategies in Learning to Write a Research Proposal: A Study of Six M.A. Students in a TEFL Program. Chinese Journal of Applied Linguistics, 35(3), 324-341. https://doi.org/10.1515/cjal-2012-0024 